\title{
Alcoholism as a risk factor for COVID-19: Boosting inflammatory response
}

\section{Authors}

Muhammad Akram $^{1}$, Mehwish Iqbal ${ }^{2}$, Marcos Altable $^{3}$ and Juan Moisés de la Serna ${ }^{4}$

1. Department of Eastern Medicine and Surgery, Directorate of Medical Sciences, GC University Faisalabad, Pakistan

2. Institute of Health Management, Dow University of Health Sciences, Karachi-Pakistan

3. Private Practice of Neurology. Neuroceuta. (Virgen de Africa Clinic). Ceuta, Spain

4. Department of Education. International University of La Rioja (UNIR). Madrid, Spain

Corresponding author email: makram 0451@ hotmail.com 


\begin{abstract}
Alcoholism is a condition associated with psychiatric and psychiatric problems, where the respiratory system is damaged through the mucociliary ladder mechanism and alveolar macrophage dysfunction. In the time COVID-19 has been observed a dramatic increase in alcohol consumption mediated by levels of anxiety and situations of confinement. In this work we analyze the relationship between alcoholism and SARS, especially with SARS-CoV-2, explained by a degradation of the host defenses of the respiratory epithelium by changing the barrier function, the discharge of cytokines and the functions of the cilia. All of them involved in the defense mechanism. of the lungs. This leads to a worse prognosis for patients precisely because of alcohol consumption. Based on this approach, alcoholism will exacerbate the consequences of COVID19.
\end{abstract}

Keywords: Alcohol, cytokine, proinflammatory, COVID-19, SARS-CoV-2 


\section{Introduction}

Lives of a huge number of people had changed intensely when pandemic of severe acute respiratory syndrome corona virus 2 appeared in 2019. The outburst commenced in December 2019 from the Wuhan city of china and till March 2020, the WHO had announced it as a pandemic 1. COVID-19 is an extremely contagious transferable disease, most frequently initiates muscular pain, fatigue, fever, dry cough and dyspnea. What differentiates this recent disease from others is its extremely quick spread and comparatively high death rate. This was endorsed in mid of the March 2020 when patients were documented in around 135 countries, approximately 12 weeks after the 1st case had appeared. On 1st March 2020, death rates extended $>3.5 \%$ in China and $1.5 \%$ in countries other than China ${ }^{2}$. The whole situation is certainly a catastrophe sensed by great numbers of individuals, leading to challenging psychological reactions. It requires substantial strength to re-adapt to an unidentified and ambiguous condition and how to deal with numerous distressing emotions, regular frustrations, and the outlook of a susceptible material presence to family and oneself. Because of the famous and recognized effects of impeding the nervous system, psychoactive ingredients including alcohol are utilized by numerous people in search of relief from anxiety, irritating or displeasing emotions, stress, or depression ${ }^{3-5}$. This entreats the query of whether the substantial escalations in sales of alcohol, observed in numerous countries are because of the pandemic when associated with the similar period in the preceding year. As an illustration, a study i.e. conducted in March 2020 by the Nielsen Company in United States of America establish 240\% escalations in sales of alcohol by means of internet, counting wines by $66 \%$, spirits by 75 percent, and beers by $42 \%$. There have also been informations in press reporting amplified domestic brutality, which has long been related with alcohol misuse ${ }^{6}$. This is not merely a financial issue or a considerable one-time incident, however a compound and complicated experience disturbing billions of people all around the world in provinces for instance: political, medical, economic, geopolitical, religious, axiological, societal, cultural, and civilizational aspects. Hence, this includes nearly all regions in the existence of societies and individuals ${ }^{7}$. 


\section{Impact of COVID 19 pandemic on mankind}

Right now the state of pandemic i.e. challenging mankind can be contemplated to be somewhat a multiple-stage complicated calamity, distressing the numerous facets of health, counting psychological health; in both individual and societal aspects ${ }^{8}$. Nevertheless the risk presented by the virus itself, numerous psychological issues may appears from the obligatory quarantine and lockdown together with the financial threats. Among other things the studies conducted upon animals have revealed the negative influence that loneliness has on enhancing stress levels in the body with both raised responsiveness to stress and neuroendocrine reactions ${ }^{9}$. All this can provoke a broad range of diseases of changing brutality, principally difficulties in concentrating, depression, anxiety, anger, insomnia, violence, and interpersonal clashes. The severity of these symptoms may at least in fragment be because of the degree and extent of the quarantine, a sensation of isolation, distress of infection, and approach to suitable or unsuitable facts and figures 10. Existing evidence proposes the involvement of organ results from uninterrupted viralencouraged and cytokine arbitrated impairment ${ }^{11}$. In the attempt to generate a reaction to the entrance of SARS-CoV-2, there is a secretion of immune cells such as pro-inflammatory cytokines which frequently becomes amplified and originates fluctuating degrees of damage to the tissues. Raised pro-inflammatory cytokines for instance TNF- $\alpha$, IL-6, IL-1, and interferon- $\gamma$ have been linked with advanced severity of disease in COVID-19 ${ }^{12}$. The pulmonary system is the principal system involved in COVID-19. Apart from general symptoms for instance sore throat, cough, and rhinitis; respiratory manifestation of acute respiratory distress syndrome (ARDS) o severe acute respiratory syndrome coronavirus (SARS) is the foremost reason of demise in corona virus disease-19 ${ }^{13}$. Additionally, there is a proof that people who have survived from this deadly COVID-19 could progress post-recovery fibrosis in lungs ${ }^{14}$. The liver is similarly influenced by COVID-19. Indicators of hepatic injury for instance raised aminotransferases, bilirubin, and GGT (gamma-glutamyl transferase) have been establish to associate with severity of disease ${ }^{15}$. Though the particular mechanism of hepatic damage is not identified, there are assumptions that this is because of viral-arbitrated damage to cell as a 
consequence of the existence of angiotensin-converting enzyme 2 in cholangiocytes and cytokinepersuaded hepatic injury ${ }^{16,17}$. Moreover, hepatic damage could messed up with the usage of antiviral drugs used in the management of Corona virus disease-19 ${ }^{17}$. Severe inflammation in muscles of pericardium, shock, arrhythmias, and cardiac failure have also been described as cardiac signs of COVID-19 ${ }^{8,18}$. Because of the existence of angiotensin converting enzyme-2 in the heart, it is considered that both viral-arbitrated and cytokine-prompted damage are accountable for damage to the cardiac muscles ${ }^{19}$. Involvement of heart with or deprived of pulmonary failure has been linked in as much as forty percent of corona virus disease deaths ${ }^{20}$. Escalated cardiac enzymes for instance creatinine kinase MB, troponin I, troponin T, and proBNP which are also indicators of cardiac damage have been establish to relate with the threat of admissions to the ICU and demises ${ }^{21}$. Proteinuria, hematuria, raised creatinine and BUN have been stated in patients of COVID-19; with approximately $5 \%$ of them coming with severe kidney damage 22,23 .

\section{Alcoholism}

Alcohol dependency, explains a state in which a person's societal role is diminished and they develop physical acceptance for alcohol and abstinence from it may cause withdrawal symptoms ${ }^{24}$. Abuse of Alcohol discusses about a form of consumption that originates adverse effects across one or more foremost domains of life (e.g. work or relationships). The lifetime incidence for depending upon alcohol ranges from country to country, fluctuating from 1.8-32.4\%. In the USA, 8 to $14 \%$ of the people are dependent upon alcohol, and $50 \%$ of those who are dependent on alcohol are possibly to become alcohol addicts ${ }^{25}$. If genders are to be concerned, then males are more anticipated to be dependent upon alcohol and abuse alcohol as compare to female, though, there has been a progressive rise in consumption of alcohol in females with a decrease in the difference amid female and male alcohol intake from the past few years ${ }^{25,26}$. Similarly, younger grownups have the greatest frequency rates of alcohol dependence and abuse, with those amid the ages of 21-25 years being the most distressed ${ }^{26}$. Apart from the distinguishable environmental factors related with alcoholism, research projects have pointed at a prospective hereditary 
susceptibility in alcohol addicts. Progresses in the area of neurobiology's research have associated alcohol abuse with neural pathways by means of which hereditary susceptibilities to consumption of alcohol can be illuminated ${ }^{25}$. Study has revealed that 18 to 27 percent of male children born to parents who regularly consume alcohol develop complications with alcohol abuse even when raised by foster parents, in contrast with 6 percent of male kids from parents who are not alcoholic. Research studies on monozygotic twins revealed that there were numerous comparisons in the consuming frequency of monozygotic twins than non-monozygotic twins ${ }^{27}$. In contrast with the popular belief that intake of alcohol in least quantities from time to time aids to prevent disorders for instance diabetes, dementia, cardiac disease and cognitive deterioration; numerous research studies have revealed that even modest consumption of alcohol contributes to more than sixty acute and persistent conditions of health ${ }^{28-30}$. Great number of health inferences of alcohol take place by means of mechanisms arising from other states of disease for instance carcinoma, hepatic ailments, high blood pressure, cardiac disease, violence, road accidents, and interpersonal clashes 28.

\section{Alcoholism and its effects on systems of the body and COVID 19}

It would be anticipated that the negative effects of alcohol on the human body become intensified when associated with COVID-19 which correspondingly has multisystemic outcomes; and so far is in itself linked with a health response of community that persuades a big deal of psychological suffering and an enhanced probability of alcohol abuse, activating a vicious cycle. The harmful effects of alcohol on the pulmonary system have been defined in various research projects Among them one is compromised mucociliary stairway mechanism because of less sensitive cilia which is an significant adjustment for the eradication of particulate material, mucus and infectious agents from the airways has been documented ${ }^{31}$. This is associated with an enhanced risk of pulmonary infections. An compromised function of pulmonary cilia has also been related to other pulmonary ailments for instance asthma, COPD, bronchiectasis, and pulmonary abscess ${ }^{32}$. In persistent alcoholics, defense mechanism of host against infectious diseases are undermine. 
Tight epithelial junctions of broncho-alveoli, an significant constituent of the innate immunity against infectious agents, are interrupted ${ }^{33}$. Additionally, alcoholism has been made known to cause dysfunction in alveolar macrophages ${ }^{34}$. The threat of ARDS has been establish to be three to four times greater in alcoholics in contrast with the common population ${ }^{32}$. An significant antioxidant, glutathione, has been revealed to be reduced in the alcoholic's alveolar epithelial substance ${ }^{35}$. Reduction in alveolar glutathione is also a distinctive discovery in acute respiratory distress syndrome which is the principal reason of demise in COVID-19 ${ }^{17,35}$. Effects on heart in alcoholics depend on the extent of use, dosage, and distinct particularities of alcohol ${ }^{36}$ extensive dosage and prolonged use of alcohol have been associated with harmful consequences on the heart 36. Diseases of cardiac muscles in alcoholic is distinguished by cardiomegaly because of hypertrophy in heart wall, expanded chambers of heart, and interstitial fibrosis; all of which come up with decreased capacity of contraction, cardiac failure, and unexpected death of heart ${ }^{37}$. Other negative effects of prolonged alcoholism on the heart comprises of dyslipidemia, hypertension, and cardiac arrhythmias ${ }^{38}$. Hepatic disease is an significant cause of alcohol-associated morbidity and fatality, because alcohol is principally processed by liver cells ${ }^{39}$. In contrast, the frequency of hepatic injury amid patients of COVID-19 varies from 14.8-53\%, described by disturbed LFTs 16.

The development process of SARS-CoV-2 contagion can be defined in 2 stages: in the 1st stage, an early inherent defense happens in an effort to give pulmonary defense. Subsequently by a resulting 2nd stage of inflammation-related tissue damage. In vulnerable people, SARS-CoV-2 infection can advance to acute viral pneumonia and can lead to acute respiratory distress syndrome (ARDS). Acute respiratory distress syndrome is a diffuse, critical, inflammatory pulmonary damage that frequently needs mechanical air circulation. In reaction to such a "storm of cytokine", unrestrained hyperinflammation can cause a failure in multiple organs. It is identified about how substantial consumption of alcohol might affect in infection of COVID-19. Whereas $<15 \%$ of drunk alcohol go into the lung, exhalation is nevertheless an important process for elimination of alcohol, as demonstrated by the common utilization of the Breathalyzer test to 
consistently evaluate levels of blood alcohol ${ }^{40}$. Excessive consumption of alcohol deeply alters inherent and adaptive immunity of lungs, leading to cause greatest degrees of viral pneumonia ${ }^{41}$, RSV infection ${ }^{42,43}$, influenza A infection ${ }^{44}$, and microbial pneumonia ${ }^{45-47}$. In 1918 Spanish flu pandemic, substantial consumption of alcohol was identified as a risk factor for deprived consequences ${ }^{48}$. Numerous current publications reporting patients of COVID- 19 failed to involve history of alcohol use ${ }^{13,49}$. More than half of the people scanned in China discusses intensifications in anxiety, depression, or stress in reaction to COVID-19 ${ }^{50}$. Throughout the period of social segregation, AUDs (alcohol usage disorders) amplified in province of Hubei in contrast with other provinces of China because of COVID-19 outburst. Hubei, the province in central china undergone a ten times escalation in harmful consumption contrasted with other provinces having smaller number of limitations ${ }^{51}$. In the US, sales of alcohol showed a 477 percent raise in April 2020 compared to the similar week in month of April $2019^{52}$. Loneliness, Social isolation and quarantine have long been identified as a inclining factor for problem of alcohol consumption ${ }^{53}$. Depending upon confined situations of economy throughout the pandemic of COVID-19, in the initial phase people may drunk a smaller amount of alcohol because of monetary limitations, but ultimately surge in consumption of alcohol was a result of enhanced stress with passage of time ${ }^{54}$. Another way alcohol can stimulate infection is because of the myths that consuming alcohol can defend against infection of COVID-19. This misconception was spread in Iran that consuming alcoholic drinks or gargling or with it would sterilize the mouth or internal parts of the body and prevent contamination by destructing the virus. Since production of alcohol is illegal in Iran, it is characteristically acquired by means of the black market. As a minimum 180 individuals in Iran expired by consuming black market alcohol that was adulterated with methyl alcohol, with more than 2500 looking for medical care 55. The misconception that alcohol averts infection of COVID-19 encouraged the WHO (World Health Organization, 2020) and the NIAAA (National Institute on Alcohol Abuse and Alcoholism, 2020) to announce that excessive consumption of alcohol does not prevent or cease COVID-19. However it has a harmful effects on innate immunity of lungs ${ }^{56}$. It has extensively been identified that alcohol damages the capability of the pulmonary system to combat infection 
57. A distinctive feature of infection COVID-19 is shortness of breath. So far Alcohol is related in number of situations with shortness of breath ${ }^{58}$, therefore implying the threat for enhanced dyspnea in the patients of COVID-19 along with alcohol use disorder. Alveolar phagocytes play an indispensable part in protecting the respiratory system from viral diseases. Rats that were deficient of alveolar phagocytes have more acute hypoxia and pulmonary failure in reaction to viral influenza ${ }^{59}$. Substantial use of alcohol considerably decreases production of pulmonary macrophage cytokine ${ }^{60}$ and intensely disturbs the functions of alveolar macrophage ${ }^{34,61}$. Alcohol also weakens the function of macrophage ensuing engulfment, as antigen demonstration, along with numbers of lymphocyte, are decreased by alcohol ${ }^{39}$. After consumption Alcohol begins to absorb by means of the ciliated epithelium straight across the respiratory circulation. Evaporation in the course of exhalation is followed by the process of condensation because the air in the trachea makes the vapors cool ultimately leading to a greater alcohol concentration ${ }^{62}$ which alters host defenses of respiratory epithelium by changing barrier function, cytokine discharge, and functions of cilia ${ }^{43}$. This modification in defense mechanism of lungs could increase the threat of getting SARS-CoV- 2 infections. Furthermore, acute respiratory distress syndrome is expected to be more severe in patients who have a damage to the pulmonary system by infectious agents including viruses. Meta-analysis of thirteen longitudinal studies establish an relationship between consumption of alcohol and the possibility of developing SARS among adults ${ }^{63}$. This proposition has thoughtful consequences as consumption of alcohol is extensive all over the world. Furthermore, alcohol is barely identified as harmful substance for the health of lungs in contrast with other organs for instance the liver generally by the public.

\section{Conclusion}

Alcohol negatively affects nearly each and every cell of the pulmonary system and a lot of these alterations strongly put those who consume alcohol in large quantity at greater risk of developing COVID-19, more severe acute respiratory distress syndrome and pneumonia. Further extensive research is required to assist in understanding how to better manage those who consume alcohol or are addicts of alcohol with COVID-19. 


\section{References}

1. Coronavirus disease (COVID-19).https://www.who.int/emergencies/diseases/novelcoronavirus-2019. Accessed March 7, 2021.

2. Baud D, Qi X, Nielsen-Saines K, Musso D, Pomar L, Favre G. Real estimates of mortality following COVID-19 infection. Lancet Infect Dis. 2020;20(7):773. doi:10.1016/S14733099(20)30195-X

3. Abrahao KP, Salinas AG, Lovinger DM. Alcohol and the Brain: Neuronal Molecular Targets, Synapses, and Circuits. Neuron. 2017;96(6):1223-1238. doi:10.1016/j.neuron.2017.10.032

4. Khantzian EJ. The self-medication hypothesis of substance use disorders: A reconsideration and recent applications. Harv Rev Psychiatry. 1997;4(5):231-244. doi:10.3109/10673229709030550

5. Zatoński W, Wojtyła A. From the editors. J Heal Inequalities. 2019;5(2):121-121. doi:10.5114/jhi.2019.91379

6. Aarø L, Zatoński W, Zatoński M, Wojtyła A. Declaration from the World Conference on Family Health, Calisia, 2019. J Heal Inequalities. 2019;5(2):129-132.

7. Badawy SM, Radovic A. Digital approaches to remote pediatric health care delivery during the COVID-19 pandemic: Existing evidence and a call for further research. JMIR Pediatr Parent. 2020;3(1). doi:10.2196/20049

8. Dong L, Bouey J, Bouey J. Public Mental Health Crisis during COVID-19 Pandemic, China. Emerg Infect Dis. 2020;26(7):1616-1618. doi:10.3201/eid2607.200407

9. Clay JM, Parker MO. Alcohol use and misuse during the COVID-19 pandemic: a potential 
public health crisis? Lancet Public Heal. 2020;5(5):e259. doi:10.1016/S24682667(20)30088-8

10. Brooks SK, Webster RK, Smith LE, et al. The psychological impact of quarantine and how to reduce it: rapid review of the evidence. Lancet. 2020;395(10227):912-920. doi:10.1016/S0140-6736(20)30460-8

11. Liu J, Zheng X, Tong Q, et al. Overlapping and discrete aspects of the pathology and pathogenesis of the emerging human pathogenic coronaviruses SARS-CoV, MERS-CoV, and 2019-nCoV. J Med Virol. 2020;92(5):491-494. doi:10.1002/jmv.25709

12. Chien JY, Hsueh PR, Cheng WC, Yu CJ, Yang PC. Temporal changes in cytokine/chemokine profiles and pulmonary involvement in severe acute respiratory syndrome. Respirology. 2006;11(6):715-722. doi:10.1111/j.1440-1843.2006.00942.x

13. $\mathrm{Wu} \mathrm{Z}, \mathrm{McGoogan} \mathrm{JM}$. Characteristics of and Important Lessons from the Coronavirus Disease 2019 (COVID-19) Outbreak in China: Summary of a Report of 72314 Cases from the Chinese Center for Disease Control and Prevention. JAMA - J Am Med Assoc. 2020;323(13):1239-1242. doi:10.1001/jama.2020.2648

14. Wang C, Pan R, Wan X, et al. Immediate psychological responses and associated factors during the initial stage of the 2019 coronavirus disease (COVID-19) epidemic among the general population in China. Int J Environ Res Public Health. 2020;17(5). doi:10.3390/ijerph17051729

15. Wong SH, Lui RNS, Sung JJY. Covid-19 and the digestive system. J Gastroenterol Hepatol. 2020;35(5):744-748.

16. Xu L, Liu J, Lu M, Yang D, Zheng X. Liver injury during highly pathogenic human coronavirus infections. Liver Int. 2020;40(5):998-1004. doi:10.1111/liv.14435

17. Musa S. Hepatic and gastrointestinal involvement in coronavirus disease 2019 (COVID19): What do we know till now? Arab $J$ Gastroenterol. 2020;21(1):3-8. 
doi:10.1016/j.ajg.2020.03.002

18. Inciardi RM, Lupi L, Zaccone G, et al. Cardiac Involvement in a Patient with Coronavirus Disease 2019 (COVID-19). JAMA Cardiol. 2020;5(7):819-824. doi:10.1001/jamacardio.2020.1096

19. Akhmerov A, Marbán E. COVID-19 and the heart. Circ Res. 2020;126(10):1443-1455.

20. Ruan Q, Yang K, Wang W, Jiang L, Song J. Clinical predictors of mortality due to COVID-19 based on an analysis of data of 150 patients from Wuhan, China. Intensive Care Med. 2020;46(5):846-848. doi:10.1007/s00134-020-05991-х

21. Shi S, Qin M, Shen B, et al. Association of Cardiac Injury with Mortality in Hospitalized Patients with COVID-19 in Wuhan, China. JAMA Cardiol. 2020;5(7):802-810. doi:10.1001/jamacardio.2020.0950

22. Cheng Y, Luo R, Wang K, et al. Kidney disease is associated with in-hospital death of patients with COVID-19. Kidney Int. 2020;97(5):829-838. doi:10.1016/j.kint.2020.03.005

23. Li Z, Wu M, Yao J, et al. Caution on Kidney Dysfunctions of COVID-19 Patients. medRxiv. March 2020:2020.02.08.20021212. doi:10.1101/2020.02.08.20021212

24. Blum LN, Nielsen NH, Riggs JA, Bresolin LB. Alcoholism and alcohol abuse among women: Report of the Council on Scientific Affairs. J Women's Heal. 1998;7(7):861-871. doi:10.1089/jwh.1998.7.861

25. Enoch MA, Goldman D. The genetics of alcoholism and alcohol abuse. Curr Psychiatry Rep. 2001;3(2):144-151. doi:10.1007/s11920-001-0012-3

26. Kranzler HR, Soyka M. Diagnosis and pharmacotherapy of alcohol use disorder a review. JAMA - J Am Med Assoc. 2018;320(8):815-824. doi:10.1001/jama.2018.11406

27. Newbury-Birch D. Impact of alcohol consumption on young people: A systematic review of published reviews. 2009 . 
28. Iranpour A, Nakhaee N. A Review of Alcohol-Related Harms: A Recent Update. Addict Heal. 2019;11(2):129-137. doi:10.22122/ahj.v11i2.225

29. Global status report on alcohol and health 2018. https://www.who.int/publications/i/item/9789241565639. Accessed March 7, 2021.

30. Griswold MG, Fullman N, Hawley C, et al. Alcohol use and burden for 195 countries and territories, 1990--2016: a systematic analysis for the Global Burden of Disease Study 2016. Lancet. 2018;392(10152):1015-1035.

31. Vander Top EA, Wyatt TA, Gentry-Nielsen MJ. Smoke exposure exacerbates an ethanolinduced defect in mucociliary clearance of Streptococcus pneumoniae. Alcohol Clin Exp Res. 2005;29(5):882-887. doi:10.1097/01.ALC.0000164364.35682.86

32. Kershaw CD, Guidot DM. Alcoholic lung disease. Alcohol Res $\backslash \&$ Heal. 2008;31(1):66.

33. Simet SM, Wyatt TA, Devasure J, Yanov D, Allen-Gipson D, Sisson JH. Alcohol Increases the Permeability of Airway Epithelial Tight Junctions in Beas-2B and NHBE Cells. Alcohol Clin Exp Res. 2012;36(3):432-442. doi:10.1111/j.1530-0277.2011.01640.x

34. Mehta AJ, Yeligar SM, Elon L, Brown LA, Guidot DM. Alcoholism causes alveolar macrophage zinc deficiency and immune dysfunction. Am J Respir Crit Care Med. 2013;188(6):716-723. doi:10.1164/rccm.201301-0061OC

35. Moss M, Guidot DM, Wong-Lambertina M, Ten Hoor T, Perez RL, Brown LAS. The effects of chronic alcohol abuse on pulmonary glutathione homeostasis. Am J Respir Crit Care Med. 2000;161(2 I):414-419. doi:10.1164/ajrccm.161.2.9905002

36. Schoppet M, Maisch B. Alcohol and the heart. Herz. 2001;26(5):345-352.

37. Leibing E, Meyer T. Enzyme und Signalwege in der Pathogenese der alkoholischen Kardiomyopathie. Herz. 2016;41(6):478-483. doi:10.1007/s00059-016-4459-8

38. El-Mas MM, Abdel-Rahman AA. Role of Alcohol Oxidative Metabolism in Its Cardiovascular and Autonomic Effects. In: Advances in Experimental Medicine and 
Biology. Vol 1193. Springer New York LLC; 2019:1-33. doi:10.1007/978-981-13-6260$6 \_1$

39. Molina PE, Happel KI, Zhang P, Kolls JK, Nelson S. Focus on: alcohol and the immune system. Alcohol Res \\& Heal. 2010;33(1-2):97.

40. Borkenstein RF, Smith HW. The breathalyzer and its applications. Med Sci Law. $1961 ; 2(1): 13-22$.

41. De Roux A, Cavalcanti M, Marcos MA, et al. Impact of alcohol abuse in the etiology and severity of community-acquired pneumonia. Chest. 2006;129(5):1219-1225. doi:10.1378/chest.129.5.1219

42. Jerrells TR, Pavlik JA, DeVasure J, et al. Association of chronic alcohol consumption and increased susceptibility to and pathogenic effects of pulmonary infection with respiratory syncytial virus in mice. Alcohol. 2007;41(5):357-369. doi:10.1016/j.alcohol.2007.07.001

43. Wyatt TA, Sisson JH, Allen-Gipson DS, et al. Co-exposure to cigarette smoke and alcohol decreases airway epithelial cell cilia beating in a protein kinase $\mathrm{C} \varepsilon$-dependent manner. $A m$ J Pathol. 2012;181(2):431-440. doi:10.1016/j.ajpath.2012.04.022

44. Greenbaum A, Chaves SS, Perez A, et al. Heavy alcohol use as a risk factor for severe outcomes among adults hospitalized with laboratory-confirmed influenza, 2005-2012. Infection. 2014;42(1):165-170. doi:10.1007/s15010-013-0534-8

45. CAPPS JA, COLEMAN GH. Influence of alcohol on prognosis of pneumonia in Cook County Hospital: a statistical report. J Am Med Assoc. 1923;80(11):750-752.

46. Fernández Solá J, Junqué A, Estruch R, Monforte R, Torres A, Urbano Márquez A. High Alcohol Intake as a Risk and Prognostic Factor for Community-Acquired Pneumonia. Arch Intern Med. 1995;155(15):1649-1654. doi:10.1001/archinte.1995.00430150137014

47. Saitz R, Ghali WA, Moskowitz MA. The impact of alcohol-related diagnoses on pneumonia outcomes. Arch Intern Med. 1997;157(13):1446-1452. 
48. Oxford JS. Influenza A pandemics of the 20th century with special reference to 1918: Virology, pathology and epidemiology. Rev Med Virol. 2000;10(2):119-133. doi:10.1002/(SICI)1099-1654(200003/04)10:2<119::AID-RMV272>3.0.CO;2-O

49. Bhatraju PK, Ghassemieh BJ, Nichols M, et al. Covid-19 in Critically Ill Patients in the Seattle Region - Case Series. $N$ Engl J Med. 2020;382(21):2012-2022. doi:10.1056/nejmoa2004500

50. Wang J, Wang BJ, Yang JC, et al. Advances in the research of mechanism of pulmonary fibrosis induced by Corona Virus Disease 2019 and the corresponding therapeutic measures. Zhonghua Shao Shang Za Zhi. 2020;36:E006. doi:10.3760/cma.j.cn50112020200307-00132

51. Ahmed MZ, Ahmed O, Aibao Z, Hanbin S, Siyu L, Ahmad A. Epidemic of COVID-19 in China and associated Psychological Problems. Asian J Psychiatr. 2020;51. doi:10.1016/j.ajp.2020.102092

52. Grocery

Business June/July 2020. http://www.qgdigitalpublishing.com/publication/?i=664264\&p=64. Accessed March 7, 2021.

53. Allen HA, Peterson JS, Whipple S. Loneliness and alcoholism: A study of three groups of Male alcoholics. Subst Use Misuse. 1981;16(7):1255-1258. doi:10.3109/10826088109039179

54. Rehm J, Kilian C, Ferreira-Borges C, et al. Alcohol use in times of the COVID 19: Implications for monitoring and policy. Drug Alcohol Rev. 2020;39(4):301-304. doi:10.1111/dar.13074

55. Delirrad M, Mohammadi AB. New Methanol Poisoning Outbreaks in Iran following COVID-19 Pandemic. Alcohol Alcohol. 2020;55(4):347-348. doi:10.1093/alcalc/agaa036

56. Yeligar SM, Wyatt TA. Alcohol and lung derangements: An overview. Alcohol. 
2019;80:1-3. doi:10.1016/j.alcohol.2019.01.002

57. Yeligar SM, Chen MM, Kovacs EJ, Sisson JH, Burnham EL, Brown LAS. Alcohol and lung injury and immunity. Alcohol. 2016;55:51-59. doi:10.1016/j.alcohol.2016.08.005

58. Cardet JC, White AA, Barrett NA, et al. Alcohol-induced respiratory symptoms are common in patients with aspirin exacerbated respiratory disease. J Allergy Clin Immunol Pract. 2014;2(2). doi:10.1016/j.jaip.2013.12.003

59. Schneider C, Nobs SP, Heer AK, et al. Alveolar Macrophages Are Essential for Protection from Respiratory Failure and Associated Morbidity following Influenza Virus Infection. PLoS Pathog. 2014;10(4). doi:10.1371/journal.ppat.1004053

60. Standiford TJ, Danforth JM. Ethanol feeding inhibits proinflammatory cytokine expression from murine alveolar macrophages ex vivo. Alcohol Clin Exp Res. 1997;21(7):1212-1217.

61. Rimland D, Hand WL. The effect of ethanol on adherence and phagocytosis by rabbit alveolar macrophages. J Lab Clin Med. 1980;95(6):918-926.

62. George SC, Hlastala MP, Souders JE, Babb AL. Gas exchange in the airways. J aerosol Med. 1996;9(1):25-33.

63. Simou E, Leonardi-Bee J, Britton J. The Effect of Alcohol Consumption on the Risk of ARDS: A Systematic Review and Meta-Analysis. Chest. 2018;154(1):58-68. doi:10.1016/j.chest.2017.11.041 